\title{
Organizações humanitárias internacionais: choques culturais entre expatriados e staff nacional
}

O número de pessoas que dependem de ajuda humanitária aumenta em todo o mundo. Para atender esta necessidade diversas organizações contemporâneas atuam em causas consideradas de interesse global, de modo transnacional, para além das fronteiras formais de Estados tradicionalmente estabelecidas. De empresas privadas a instituições religiosas, chamam a atenção aquelas organizações ligadas a atividades de natureza humanitária porque são compostas por sujeitos de várias origens e culturas, trabalhando temporariamente em contextos adversos. Esse trabalho surgiu da constatação empírica de que alguns conflitos entre profissionais locais e estrangeiros eram recorrentes nas diversas missões vivenciadas por um dos autores numa organização humanitária. 0 fato era que, apesar da ONG aqui estudada tratar formalmente em sua página da internet da diversidade cultural que o profissional poderá encontrar no campo, nenhum tipo de treinamento sobre relações culturais é verdadeiramente oferecido. O objetivo é discutir a inserção de questões culturais no planejamento de uma operação humanitária, baseada em relato de experiência e revisão da literatura sobre o assunto. Nossas conclusões apontam para a necessidade de aprofundamento do entendimento das questões cultuais nesse campo, onde os trabalhadores locais têm uma percepção de que estas organizações compreendem pouco da cultura local e que o resultado da operação pode ser impactado por isso.

Palavras-chave: Administração; Cultura; Operações Humanitárias; Organizações Humanitárias Internacionais.

\section{International humanitarian organizations: cultural shock between expatriates and national staff}

\begin{abstract}
The number of people who depend on humanitarian aid increases worldwide. To meet this need, a number of contemporary organizations operate in causes considered of global interest, transnationally, beyond the formal boundaries of traditionally established states. From private companies to religious institutions, we drawn to those organizations linked to activities of a humanitarian nature, because they are composed of subjects from various backgrounds and cultures working temporarily in adverse contexts. This work arose from the empirical observation that some conflicts between local and foreign professionals were recurrent in the various missions experienced by one of the authors in a humanitarian organization. In fact, although the NGO studied here formally treats in its website of cultural diversity that the professional can find in the field, no type of training in cultural relations is truly offered. The objective of this paper is to discuss the insertion of cultural issues in the planning of a humanitarian operation, based on an experience report and literature review on the subject. Our conclusions point to the need to deepen the understanding of cultural issues in this field, where local workers have a perception that these organizations understand little of the local culture and that the result of the operation can be impacted by this.
\end{abstract}

Keywords: Administration; Culture; Humanitarian Operations; International Humanitarian Organizations.

\section{Topic: Recursos Humanos}

Reviewed anonymously in the process of blind peer.
Received: 13/01/2017

Approved: 14/03/2017
Marcos Antônio de Souza Barbosa

Universidade Federal de Sergipe, Brasil

http://lattes.cnpq.br/4389333162088886

marcos asb@yahoo.com

Renata Oliveira Silva

Northern Kentucky University, Estados Unidos

http://lattes.cnpq.br/7420943966354000

reoliveir@gmail.com
Referencing this:

BARBOSA, M. A. S.; SILVA, R. O.. Organizações humanitárias internacionais: choques culturais entre expatriados e staff nacional. Revista Brasileira de Administração Científica, v.8, n.1, p.93-102, 2017. DOI: http://doi.org/10.6008/SPC2179-684X.2017.001.0008

DOI: $10.6008 / S P C 2179-684 X .2017 .001 .0008$ 


\section{INTRODUÇÃO}

As operações humanitárias têm aumentado em número e em complexidade, e a quantidade de pessoas que dependem de ajuda cresce em todo o mundo devido ao aumento de desastres naturais, biológicos, conflitos armados, refugiados e fome. No ano de 2016, além do deslocamento humano causado por conflitos de longo prazo em lugares como Síria e Sudão do Sul, houve também um aumento da violência na República Centro-Africana e a fome causada por El Niño, que trouxe mais seca para as regiões do sul da África.

As Nações Unidas projetam que, pelo menos, 87 milhões de pessoas em dezenas de países precisarão de ajuda humanitária no próximo ano e estão buscando um recorde de US\$20,1bi para atender às suas necessidades. O Escritório das Nações Unidas (ONU) para a Coordenação de Assuntos Humanitários (OCHA) informou que para ajudar 57 milhões de pessoas em 2015, a ONU precisou de 16,4 bilhões de dólares. 80\% destes fundos serão destinados para os países que atravessam conflitos em que a violência tem causado grandes impactos na vida das pessoas. Somente as crises no Sudão do Sul, na República Centro-africana, no Iraque e na Síria, representam 70\% das necessidades globais de financiamento ONU (2014).

Para que estas operações sejam viabilizadas são necessários cada vez mais profissionais competentes nesta área de atuação e que queiram participar destas missões. O alerta foi dado pela OCHA no Dia Mundial da Ação Humanitária, 19 de agosto de 2014. Na mesma data, a organização Médicos sem Fronteiras (MSF) chamou a atenção de que mais profissionais para trabalhar são essenciais para ajudar a implementar e a desenvolver novas abordagens e estratégias (LABOISSIÈRE, 2014). A tentativa é sensibilizar as pessoas para as questões humanitárias e para os esforços de cooperação internacional para apoiar os que se encontram em situação de extrema vulnerabilidade.

Para atender esse tipo de necessidade, diversas organizações contemporâneas atuam em causas consideradas de interesse global, de modo transnacional, para além das fronteiras formais de Estados tradicionalmente estabelecidas. De empresas privadas a instituições religiosas, chamam a atenção aquelas organizações ligadas a atividades de natureza humanitária porque são compostas por sujeitos de várias origens e culturas trabalhando em contextos ricos em diversidades sociais e culturais.

A literatura define a operação humanitária como uma acelerada resposta a "eventos calamitosos súbitos", sejam eles naturais ou impactados pelo homem. Kovacs et al. (2009) afirma que os maiores desafios estão relacionados à coordenação das diferentes atividades logística. Entretanto, a maior parte da literatura, bem como os estudos seminais sobre o tema, está focada na investigação de soluções de otimização de frotas e distribuição de recursos para as vítimas dos desastres (SCARPIN et al., 2014) e no planejamento das atividades logísticas (OVERSTREET et al., 2011).

Nos últimos anos, porém, começam a surgir artigos que vem ampliando o seu escopo para incluir todos os processos da gestão da cadeia de suprimento (SCARPIN et al., 2014; TATHAM et al., 2010). Um dos principais desafios das operações humanitárias está relacionado à colaboração e o envolvimento de diversas organizações e o papel de cada uma delas durante as diferentes etapas da operação humanitária, pois são 
organizações com culturas e contextos diferentes entre si e também distintas dos beneficiários (KOVÁCS et al., 2009; TATHAM et al., 2010).

Esse trabalho surge da vivência de um dos autores em diversos tipos de operações humanitárias, tais como em zona de conflito, nutrição (fome), epidemia (HIV/AIDS) e deslocamentos humanos (refugiados) e da sua observação de conflitos de cunho cultural entre os profissionais locais e os estrangeiros. O fato era que, apesar de a ONG aqui estudada tratar formalmente em sua página da internet da diversidade cultural que o profissional poderá encontrar no campo, nenhum tipo de treinamento sobre relações culturais é verdadeiramente oferecido.

Assim, a partir de experiências de campo, surgiu a ideia de contribuir para o entendimento das relações entre operações com sistemas de gestão padronizadas e a diversidade cultural dos trabalhadores, existente nesses ambientes específicos e complexos. A pergunta é: como atingir resultados organizacionais através de padrões de gestão aplicados (ou impostos) em ambientes multiculturais em situações de emergência e conflito armado? As organizações podem, por exemplo, por questões de danos à imagem, não querer reconhecer esses desencontros. Nós nos lançamos na investigação para entender como as diferenças culturais existentes entre os profissionais expatriados e locais acontecem para além da imagem e discurso oficial das organizações.

\section{METODOLOGIA}

Optamos por não citar a organização e nomes dos ativistas para facilitar o acesso e para não comprometer nossa investigação com restrições burocráticas. Trata-se de uma organização internacional, não governamental e sem fins lucrativos que oferece ajuda médica e humanitária a populações em situações de emergência, em casos como conflitos armados, catástrofes, epidemias, fome e exclusão social. Proporciona também ações de longo prazo na ajuda a refugiados, em conflitos prolongados, instabilidade crônica ou após a ocorrência de catástrofes naturais ou provocadas pela ação humana. A organização foi criada com a ideia de que todas as pessoas têm direito a tratamento médico e que essa necessidade é mais importante do que as fronteiras nacionais. A organização é composta de profissionais estrangeiros e pelas equipes locais, sendo financiada por contribuições na sua maioria de pessoas físicas.

Conscientes ou não, por vezes ocultos, os conflitos culturais existem e é na perspectiva dos profissionais locais que atuam ou atuaram na organização que se desenvolveu o estudo. Não foi explorado nenhum outro tipo de interesse que não estivesse ligado às relações culturais. No âmbito desse trabalho, definimos Organizações Humanitárias Internacionais como aquelas que atuam em causas que envolvem o atendimento de populações em situação de risco através de assistência material ou logística, normalmente em resposta a crises humanitárias, incluindo desastres naturais e provocados pelo homem. Entendemos também que o principal objetivo da ajuda humanitária é salvar vidas, aliviar sofrimentos e manter a dignidade humana.

Os ativistas são aqueles que atuam nessas organizações, têm identificação com a causa, atuam de forma voluntária ou remunerada com contratos de trabalho e benefícios diversos e colocam seu tempo, sua 
força de trabalho e especialidades a serviço de missões. Podem atuar em seu próprio país ou fora, os chamados expatriados, assumindo o status de Staff nacional ou internacional.

Qualitativa, abordamos o problema de forma exploratória, visando proporcionar maior familiaridade com o problema com vistas a torná-lo explícito ou a construir hipóteses (GIL, 2006). Aproximamos da categoria de pesquisa Estudo de Caso, cujo objeto é a unidade que se analisa profundamente (TRIVIÑOS, 1987), tendo como prioridade questões referentes ao estabelecimento e manutenção de conflitos culturais que acontecem em uma organização humanitária. A principal categoria que subsidiou a análise foi a Cultura e os conceitos relacionados: Mobilidade, Identidade e Poder.

Estudar o ativismo internacional é lançar-se a uma heterogeneidade de organizações, quer seja em termos das causas, contextos, estruturas e formas de organização do trabalho. O campo empírico é uma organização não governamental, mais especificamente uma organização sem fronteiras de atuação em causas humanitárias, levando-se em conta sua representatividade na participação e presença como referência mundial na sua área.

Nesse artigo, consideramos como fonte primária a vivência profissional e ativista na área humanitária, com suas inquietações e observações de alguns conflitos de cunho cultural entre os profissionais nacionais e os estrangeiros. Os resultados integrados na discussão do trabalho formaram um conjunto que fornece subsídios para o estabelecimento de relações, tanto do ponto de vista empírico quanto do ponto de vista teórico, no sentido de atender aos objetivos do estudo das organizações não governamentais internacionais e de atuação social.

\section{DISCUSSÃO TEÓRICA}

A cultura é um tema amplo que envolve diferentes perspectivas teóricas, vertentes históricas, tendências e articulações, em sentido amplo envolve todo o conjunto de obras humanas (MELLO, 1986). Nosso objetivo aqui é aproximar ao máximo essa categoria ao campo das atuações profissionais humanitárias, onde o ambiente multicultural está bastante em evidência e por isso nossa proposta de estudo a partir dos encontros e desencontros advindos da diversidade, sobretudo cultural desses ambientes. A cultura, em suas diferentes concepções, foi pensada por vezes mais como um conjunto de traços, crenças e costumes ordenados de forma estática do que como uma estrutura dinâmica que se transforma pelo processo histórico. Assim, cultura assimilou uma concepção naturalizada, como conjunto de caracteres visíveis e hereditários dentro de um agrupamento humano.

O homem é essencialmente um ser de cultura, resultado de um longo processo de hominização iniciado há aproximadamente quinze milhões de anos, onde numa passagem de adaptação genética ao ambiente natural a uma adaptação cultural, resultou numa incrível regressão dos instintos, progressivamente 'substituídos' pela cultura. Assim, para Cuche (1999), a cultura permite ao homem não somente adaptar-se a seu meio, mas também adaptar este meio a si próprio, as suas necessidades e seus projetos, "a cultura torna possível a transformação da natureza" (CUCHE, 1999). 
A noção de cultura serve, portanto, para desconstruir as explicações naturalizantes dos comportamentos humanos e isto implica dizer que "a natureza do homem é inteiramente interpretada pela cultura" (CUCHE, 1999). Nada é puramente natural no homem. Mesmo as necessidades fisiológicas, como a fome, o sono, o desejo sexual, etc., são informadas pela cultura, orientando e informando os diferentes modos de satisfação de tais necessidades. A divisão sexual dos papéis e das tarefas são exemplos citados pelo autor como resultados fundamentalmente da cultura e por isso varia de uma sociedade para outra.

Como acontece com relação aos seus modos de vida e de crença, o conceito de cultura torna-se necessário para explicar de forma mais satisfatória a questão da diferença entre os povos e os estudos sobre o encontro de culturas distintas podem evidenciar modalidades muito variadas e levar a resultados extremamente contrastantes segundo as situações de contato. Visto de fora, por outro grupo, crenças religiosas podem evidenciar diferenças que geram conflitos, por exemplo.

Julgar o que é certo e errado em outra cultura pode nos levar à xenofobia, conceito que veremos mais à frente e que representa intolerância ao que é diferente, ao estrangeiro. O outro pode não se sentir mal nem oprimido e ter direito de escolher viver a partir das regras e costumes de seu grupo. Porém, opressão não é uma questão de perspectiva, está no âmbito da violência simbólica e física. A questão deve ser: qual o nível de consciência do sujeito da sua condição social em relação aos vários mecanismos de sobrevivência e de oportunidades para se tornar um sujeito possuidor de igualdade de direitos?

Quando as relações sociais são postas, são desafiadas porque as pessoas mudam de lugar e deixam seus locais de origem e vínculos afetivos mais profundos de forma voluntária ou não, a análise cultural toma uma outra vertente: os estudos da mobilidade humana. Freitas (2009) analisa a mobilidade como um capital simbólico no mundo organizacional a partir de três premissas: a primeira é que a mobilidade já é uma necessidade social e organizacional; segundo que a transformação da necessidade da mobilidade na virtude em ter mobilidade é uma legitimação ideológica e valorização desta como capital simbólico e, por fim, que a expatriação de profissionais e a circulação de empresas no mundo traduz um novo tipo de nomadismo, que não pode negar a mobilidade como um valor. Conceitua mobilidade como:

A capacidade, a disposição e o desejo que um indivíduo tem de mudar geograficamente e de interagir com diferenças em relação à sua cultura, à sua profissão, à sua empresa, ao seu cargo e aos seus saberes, fazendo ajustes que favorecem o seu melhor desempenho profissional e enriquecem a sua vida pessoal; ou seja, um indivíduo aberto a experiências novas, que confrontem e alarguem os limites dos seus conhecimentos, de suas experiências pessoais e profissionais, bem como as suas certezas culturais (FREITAS, 2009).

Dessa forma esse conceito vai além de transposições geográficas e envolve, segundo Freitas (2009), "um conjunto complexo de disposições e competências que coloca o indivíduo em interação com um outro, diferente de si, permitindo-Ihe vivenciar a alteridade no seu exercício profissional e na sua vida pessoal" (FREITAS, 2009). O conceito de capital simbólico foi tomado de empréstimo dos estudos realizados por Bourdieu e nos seus trabalhos com Passeron em que propuseram e analisaram mecanismos por meio dos quais se efetiva a reprodução social de disposições, gostos e valores, repassados de uma geração a outra. A partir desse conceito, a autora argumenta que existe um viés ideológico no fato de a mobilidade começar a 
aparecer como uma opção exclusivamente individual quando ela é, também, uma necessidade fundada em uma realidade organizacional concreta:

Entendemos que existe uma necessidade organizacional real de indivíduos "facilmente adaptáveis culturalmente" e desejosos de uma forma de vida móvel. No entanto, tudo se passa como se a mobilidade fosse fruto exclusivo de um desejo genuíno do indivíduo e não, também, uma exigência para as empresas competirem neste novo mundo econômico (FREITAS, 2009).

Afirma objetivamente que as empresas não assumem a sua dependência desse tipo profissional, apenas trata como se elas lhe abrissem as portas, dando-Ihes uma oportunidade diferencial, quando este diferencial é condição competitiva para elas no mercado global (FREITAS, 2009). Assim, a partir do conceito de capital simbólico e do viés ideológico articulados, a autora defende a tese de que a mobilidade representa, nos dias atuais, um novo capital no mundo profissional que inclui as disposições e os desejos dos indivíduos em rodar o mundo profissionalmente, bem como os acessos e os caminhos institucionais, representados tanto pelos diplomas, como pelo conjunto de competências que reproduzem os valores das empresas, escolas, universidades e mídia especializada em negócios e carreiras (FREITAS, 2009).

A legitimação da mobilidade está cada vez mais baseada na natureza psicológica encontrada nos discursos quotidianos, ideologicamente influenciados, onde uma nova forma de nomadismo, está perfeitamente atrelada às novas necessidades das grandes empresas de caráter mundial (FREITAS, 2009). São organizações que vem de outro mundo? Para muitos o mundo ainda é dicotômico, separados por históricas fronteiras econômicas, sociais e culturais. Aqui apresentamos algumas das várias origens dos conflitos culturais.

O clima de conflito era recorrente nas missões como apontam essas falas: 'Já faço um favor, ainda vai reclamar?', de uma profissional local referindo-se a maneira em que algumas respostas eram dadas por expatriados, profissionais vindos de outros países para participar da missão, sobretudo europeus. Ou: 'Nem todos vão com a cabeça aberta!', sobre os expatriados que não estavam completamente inseridos nas questões humanitárias e culturas locais. Por outro lado, o dos estrangeiros: 'Não tem essa coisa de vamos construir juntos, é protocolo!', de um chefe de missão justificando as decisões urgentes e padronizadas que tomava. A relação entre estrangeiros se traduzia em 'você para mim é uma folha em branco, mas eu vou te observar', uma frase recorrente de um superior expatriado dando a entender que não tinha preconceitos de nenhuma espécie, mas que iria ficar em alerta em relação ao desempenho do profissional local.

No campo de ação dessas ONG muitas vezes parece haver um conflito entre países historicamente colonizadores versus colonizados e, como consequência, para alguns expatriados, mandar é completamente natural, algo como 'eu sei o que é melhor para você!'. Há também a questão da alta rotatividade do staff expatriado, porque muitos cumprem apenas uma missão com período médio de seis meses. Muitos jovens estrangeiros vão para organizações humanitárias e depois de seis meses de trabalho recebem seis meses de seguro desemprego de seus países e vão viajar. Esse é o único interesse de muitos. Em missões mais complexas, no caso da assistência aos atingidos pelo Ebola na África, por exemplo, a jornada de trabalho é de três semanas de trabalho, mais uma quarentena. Por conta dessa alta rotatividade surgem problemas de integração. 
Nunca antes as operações humanitárias contaram tanto com o Staff Nacional. A remuneração é baixa para padrões internacionais, mas alta para padrões locais. O pessoal do terreno, termo usado para se referir aos profissionais envolvidos com atividades operacionais e hierarquicamente inferiores, são de maioria local e geralmente moram em alojamentos em média com sete pessoas por habitação. Para os expatriados a remuneração pode vir acompanhada de benefícios inclusive para esposo ou esposa que também recebem percentual de renda. No caso dos chefes de missão e coordenação alguns contam com casa com empregada e motorista, com direito a escola internacional para os filhos que crescem numa espécie de 'nata' social.

Em relação à segurança, em algumas missões o desafio é trabalhar rodeado por gente armada por todos os lados. Os riscos nas missões humanitárias são inúmeros e o número de mortos no ano de 2014 foi maior do que o ano passado, considerando que nem sempre notícias são divulgadas. Vive-se numa pressão ambiental, física e mental alta e por muito tempo, onde o desafio é trabalhar a tolerância tendo a vida de ativistas e população atendida em jogo. Com maiores responsabilidades, os cargos de destaques são mais tensos devido ao nível de liderança exigido, capacidade de negociação com a alta direção, administração de escassos recursos financeiros. $O$ fato é que existe uma relação de trabalho e consequentemente de poder e não de militância ou voluntariado neutra simplesmente.

\section{CONCLUSÕES}

O indivíduo supõe um sujeito dotado de razão e autonomia de pensamento e ação que o afasta das concepções religiosas e tradicionais. A identidade é entendida como o conjunto de características que formam os indivíduos singulares e que informam aos outros códigos sobre como agir e se relacionar em relação aos demais. Entre em cena a singularidade que está nas múltiplas identidades assumidas de gênero, de raça e etnia, de orientação sexual, de classe etc. A combinação de várias categorias faz de cada um de nós pessoas únicas, cuja unidade se converte no nome, por exemplo.

O etnocentrismo está relacionado a supervalorização da própria cultura em detrimento das demais, gerou e ainda gera muita intolerância, preconceito e discriminação. É uma "visão de mundo onde nosso próprio grupo é tomado como centro de tudo e todos os outros são pensados e sentidos através de nossos valores, modelos e definições do que é existência" (ROCHA, 1994). Etnocentrismo denota a maneira pela qual um grupo, identificado por sua particularidade cultural, constrói uma imagem do universo que favorece a si mesmo. Mentalidade que considera sua própria etnia e seus valores culturais superiores aos demais, portanto é uma tendência de julgar os estrangeiros e diferentes usando como parâmetro seu próprio grupo étnico.

O preconceito, tal como a palavra expressa, trata-se de um conceito pré-estabelecido sem uma lúcida apreciação ou contextualização dos fatos. Sempre de caráter depreciativo, leva a estereotipar pessoas ou grupos e a cristalizar crenças e clichês. Pior, leva a discriminação, prática que consiste em negar iguais oportunidades e/ou direitos a um grupo social, racial, sexual, religioso e etc. Pode assumir formas sutis, não declaradas e as consequências são nefastas, não somente para as pessoas e os grupos discriminados, mas também para toda a sociedade. 
A diferença é ameaçadora porque fere nossa própria identidade cultural. Ao outro negamos aquele mínimo de autonomia necessária para falar de si mesmo e termina gerando a intolerância, repúdio, por parte de pessoas ou de um grupo, da especificidade e diferença de outros. A intolerância consiste na negação do direito à diferença de comportamentos sociais, opções sexuais, escolhas religiosas, etc. Uma das consequências mais conhecidas e infelizmente ainda presente é a xenofobia, repulsa ao que é e a quem é estrangeiro.

Um dos caminhos é ver as coisas do mundo como a relação entre elas, ver que a verdade está mais no olhar que naquilo que é olhado e por fim não transformar a diferença em hierarquia ou em bem e mal, mas vê-la na sua dimensão de riqueza por ser diferença. Na organização investigada nesse trabalho os choques culturais entre seus trabalhadores e entre eles e o meio em que virão a atuar, são previstos formalmente na página oficial da internet e nas seleções, porém no campo as assimetrias de poder ficam evidentes principalmente porque tem origem nos preconceitos de origem, etnia, história e cultura.

O expatriado é o estrangeiro que chega ao local de destino com um contrato de trabalho na mão para trabalhar na unidade ou missão da organização à qual já está ligado. (FREITAS et al., 2011). As suas características individuais de estrangeiro (de seu país, de sua cidade, de sua etnia, de sua cultura) não são percebidas como individuais, mas à sua origem estrangeira, segundo Schütz $(2013$, citado por FREITAS et al., 2011).

Ele é visto e sentido como estrangeiro de um tipo determinado. No entanto, para o estrangeiro que se insere em um grupo, os demais não são simples executantes de funções típicas anônimas, mas indivíduos; ele é inclinado a tomar por caráter individual o que é típico, edificando o mundo social feito de um pseudoanonimato, uma pseudointimidade e pseudotipicalidade.

No artigo 'Das identidades aos processos identitários: repensando conexões entre cultura e poder', Marcelo A. Ennes e Frank Marcon analisam o que chamam de usos superficiais da noção de identidade. Implicada fundamentalmente por relações de poder, apontam caminhos para a pesquisa sobre processos identitários necessários para reflexão e possibilidades de análise dos processos de construção de identidades, trabalhando com quatro parâmetros: os atores, as disputas, as normas e os contextos. Os atores sociais de algum modo articulados a grupos, os motivos de disputas de pertencimento ou não a tais grupos, os elementos morais e normativos que regulam o meio pelos quais estes atores entram em interação pelo que disputam e os contextos históricos e sociais nos quais são produzidos e, ao mesmo, contribuem para sua produção

$\mathrm{Na}$ organização estudada os atores sociais considerados eram os profissionais distribuídos em diversas posições hierárquicas e funções, reunidos uma estrutura organizacional. Os motivos de ligação sujeito/grupo está na causa, forte ponto de vínculo compartilhado por todos. Os elementos morais e normativos estavam relacionados às disputas e desentendimentos mais ligados às operações, divisão de trabalho e relações de poder, como constataremos mais à frente nas análises. Os contextos históricos e sociais estão no campo multicultural de atuação da organização e indivíduos, uma "torre de babel" regulada por modelos de gestão que muitas vezes desconsidera ou subestima as individualidades dos profissionais, no caso dessa pesquisa dos profissionais locais, e identidade dos grupos. 
Ennes et al. (2014) criticam diretamente os usos essencializadores e naturalizadores e propõem estabelecer parâmetros analíticos para compreender o que chamam de dinâmicas de hierarquizações e transgressão social. "Geralmente as análises não ressaltam a dimensão política, que firmam a identidade como fenômeno social" (ENNES et al., 2014). Diversidade e pluralidade cultural, comumente usadas para se referir a identidade, mas em sentido estático, sem abordar novas expressões das relações de dominação e poder.

A negligência com o ativista local precisa de mais provas e debates, mas aqui nesse recorte de pesquisa baseado na vivência e entrevistas com atores ainda em ação, ficou claro que implantar um sistema de gestão e produção gestão padronizados não surtiam efeitos satisfatórios quando a cultura local e dos indivíduos locais resistiam por qualquer que fosse o motivo. $O$ fato é que as expressões ocultas (ainda sobre a ótica dos autores e percebida por nós no campo) sob ideias enfáticas e aparentes de respeito às diferenças, não capturam as dinâmicas e as implicações de pertencimento e alteridade como processos relacionais verdadeiramente existentes no campo.

Ainda em relação a proposta de reflexão sobre os processos identitários, Ennes et al. (2014) afirma que essa reflexão deve ser envolvida pela abordagem, descrição e compreensão das relações de poder que envolvam marcadores sociais tornados relevantes como caracterizadores de distinção. Procuram assim evitar a reessencialização das identidades e compreendê-las fundamentalmente como relacionais; também analisar as ambiguidades e ambivalências dos processos sociais que criam e recriam formas de subordinação e hierarquização, ao mesmo tempo que expressam formas de contestação e transgressão social; e por fim, procuram compreender os processos de emergência e (re)inserção social de atores em contextos sociais, políticos e culturais que são caracterizados pelo descentramento, pela fragmentação e pela efemeridade.

Assim, Ennes et al. (2014), os conflitos e embates passaram oferecer uma nova base política para novas formulações teóricas em que a cultura e a subjetividade ganharam maior relevância. Para nós pesquisadores, percebemos o universo teórico que poderia dar suporte para nossas análises ao tempo que nos deu segurança em relacionar os conflitos culturais com as disputas de poder, em fim, um vasto universo!

A diversidade étnica, cultural, de gênero, orientação sexual, deficiência física, mental ou intelectual, faixa etária e religião, entre outras, presentes nas organizações humanitárias internacionais são apropriações espontâneas, mas, também, apropriações deliberadas do meio social através de normas, discursos e imagens construídas com objetivos variados, que vai desde recrutamento, seleção e adequação de profissionais até a implantação de urgentes e complexos processos de trabalho em ambientes multiculturais. Nesse contexto, o desafio ainda continua em apontar caminhos para compreensão da inserção de questões culturais no planejamento de uma operação humanitária e identificar como características da cultura, particularmente presentes nas relações de poder no dia a dia do trabalho, influenciam o alcance de resultados organizacionais.

A vivência e os depoimentos espontâneos aqui apresentados demonstram que os trabalhadores locais, os Staffs nacionais como também são conhecidos, tem uma percepção de que a organização compreende pouco da cultura local e que o resultado da operação é impactado por isso. São diversas 
emoções que afloram e que levam a conflitos que em outros contextos não tomariam tamanha dimensão. Desempenho profissional e produtividade organizacional mudam se você respeita o outro e o respeito cultural, e no ambiente organizacional aqui estudado, faz surgir novas possibilidades de olhares sobre os estudos culturais e estudos da cultura organizacional.

O desafio continuará sempre sendo pensar a questão da diversidade como uma política organizacional essencial, voltadas a atender a um contexto e a um campo amplo e diverso como é o caso das organizações humanitárias, para que sejam efetivamente aceitas por todos, profissionais expatriados, profissionais locais e população atendida.

Se as ONGs pretendem resultados eficientes em melhoria de qualidade de vida de seus trabalhadores, que sejam ambientes mais humanos, porque "ser humano" é um ser a partir de um conjunto de contradições. Trabalhar a valorização e respeito da diferença expondo a diversidade cultural é importante caminho para combater o preconceito derivado, pincipalmente, do etnocentrismo ainda e surpreendentemente presente nessas organizações que se pretendem multicultural por natureza.

\section{REFERÊNCIAS}

CUCHE, D.. A noção de cultura nas ciências sociais. Bauru: EDUSC, 1999.

ENNES, M. A.; MARCON, F.. Das identidades aos processos identitários: repensando conexões entre cultura e poder. Sociologias, Porto Alegre, v.16, n.35, p.274-305, 2014.

FREITAS, M. E.. A mobilidade como novo capital simbólico nas organizações ou sejamos nômades?. O\&S, Salvador, v.16, n.49, p.247-26, 2009.

FREITAS, M. E.; DANTAS, M.. O estrangeiro e o novo grupo. Revista Administração de Empresas, São Paulo, v.51, n.6, p.601-608, 2011.

GIL, A. C.. Como elaborar projetos de pesquisa. São Paulo: Atlas, 2006.

KOVAC'S, G.; SPENS, K.. Identifying challenges in humanitarian logistics. International Journal of Physical Distribution \& Logistics Management, v.39 n.6, p.506-528, 2009. DOI: http://doi.org/10.1108/09600030910985848

LABOISSIÈRE, P.. Número de pessoas que precisam de ajuda é o mais alto na história, alerta ONU. Brasília: EBC Agência Brasil, 2014

MELLO, L. G.. Antropologia Cultural. Petrópolis: Vozes, 1986.
ONU. Organização das Nações Unidas. Para ajudar 57 milhões de pessoas, ONU precisará 16,4 bilhões de dólares em 2015. Brasília: ONU, 2014.

OVERSTREET, R. E.; HALL, D.; HANNA, J.; RAINER, R. K.. Research in Humanitarian Logistics. Journal of Humanitarian Logistics and Supply Chain Management, v.1, n.2, p.114131, 2011. DOI: http://doi.org/10.1108/20426741111158421

ROCHA, E.. O que é etnocentrismo. São Paulo: Brasiliense, 1994.

SCARPIN, M. R. S.; SILVA, R. O.. Humanitarian Logistics: Empirical Evidences from a Natural Disaster. Procedia Engineering, v.78, p.102-111, 2014.

TATHAM, P. H.; PETTIT, S. J.. Transforming humanitarian logistics: the journey to supply chain management. International Journal of Physical Distribution and Logistics Management, v.40, n.9, p.609-622, 2010. DOI. http://doi.org/10.1108/09600031011079283

TRIVIÑOS, A. N. S.. Introdução à pesquisa em Ciências Sociais: a pesquisa qualitativa em Educação. São Paulo: Atlas, 1987. 